\title{
HISTORIOGRAFIA E MÁQUINAS DE GUERRA: A HISTÓRIA DA HISTÓRIA COMO UM ESTUDO DE RELAÇÕES DE FORÇAS COM BREVES APONTAMENTOS SOBRE A ESCOLA Histórica Alemã e a Escola dos AnNales*
}

\author{
Julio Bentivoglio** \\ juliobentivoglio@gmail.com
}

Resumo: Este texto procura analisar a Escola Histórica Alemã e a Escola dos Annales tomando o conceito de máquinas de guerra - perspectiva aberta por Deleuze - e as reflexões em torno da operação historiográfica de Michel de Certeau. Ele indica como relações de força no interior da historiografia e a criação de dispositivos específicos, as revistas de história, marcam o avanço deste saber, a História, que se constitui como um campo excêntrico, cujos efeitos se fazem irregularmente no tempo e no espaço, visto que ela é ao mesmo tempo um lugar, uma disciplina e uma escrita, que se constitui na tensão com outros saberes e das disputas entre diferentes correntes historiográficas.

Palavras-chave: Teoria da história, Historiografia, Máquinas de guerra.

Contemplar a história da historiografia é sempre um exercício fecundo para melhor se compreender as reflexões epistemológicas no interior da história e a formação de determinadas práticas historiográficas que se constituem ao longo do tempo como referenciais. Este texto procura a partir da análise do surgimento de duas escolas que tiveram destaque no avanço do conhecimento histórico mostrar como relações de força marcam a institucionalização do campo, delimitando grupos e constituindo correntes teórico-metodológicas. Assim, a gênese tanto da Escola Histórica Alemã quanto da Escola dos Annales será tomada, em linhas bastante gerais, para

\footnotetext{
* Uma primeira versão dessa pesquisa foi apresentada no V Simpósio Internacional de História - Culturas e Identidades - ANPUH/GO, realizado na UFG em 2011.

** Doutor em História pela USP. Professor do Programa de Pós Graduação em História e do Departamento de História da Universidade Federal do Espírito Santo.
} 
se discutir a própria história da história como o surgimento e a expansão de máquinas de guerra, conceito caro ao pensamento de Gilles Deleuze. Embora sejam conhecidas as disputas entre posturas historiográficas distintas, deve-se também lembrar que elas existem até mesmo no interior de um mesmo paradigma - algumas correntes marxistas são evidências claras desse fenômeno - analisá-las pode ser um exercício fecundo. Pretende-se, portanto, indicar como polêmicas, dissidências e lutas intestinas fomentam novas correntes ou abordagens históricas, que podem levar tanto à formação das escolas, quanto em sua disseminação irregular no tempo e no espaço, fazendo com que posturas historiográficas distintas surjam, em meio à permanência e influência de outras mais antigas.

Não é novidade alguma dizer que existem disputas na História. Algumas virulentas, outras mais amenas, marcadas pela elegância e circunspeção. E que as rivalidades surgem, às vezes, não exatamente nos mestres ou nos fundadores, mas em seus discípulos e em supostos herdeiros. No interior da história da historiografia existem casos e mais casos de ampla variedade sobre estes conflitos, seus contendores e a respeito das questões em foco. E é curioso o interesse e o frisson que estas rivalidades provocam quando mencionadas em disciplinas, cursos, congressos e mesmo quando as encontramos nas páginas de algum livro. É fato que as polêmicas são sempre acompanhadas com atenção. No entanto, longe de querer alimentá-las, visto que até podem ter sua utilidade no debate e avanço da historiografia, tomo-as não para incentivar preconceitos ou interpretações equivocadas, mas, para aclarar o estudo do campo.

As diferenças entre perspectivas historiográficas sempre existiram e, invariavelmente, é a reação e a contestação a um determinado tipo de prática histórica que levam à formação e ao desenvolvimento de novas abordagens, de novos paradigmas - e não somente as carências de sentido. Muitas vezes a própria diferença ou a contradição dos sentidos existentes e não a simples dinâmica da tradição determina o nascimento de novas correntes historiográficas. De qualquer modo, é irresistível não escapar um sorriso quando ouvimos Leopold von Ranke ser chamado de historiador eunuco, por seu rival na Universidade de Berlim: Droysen (2009, p.7). Ou do sarcasmo de Lucien Febvre sobre Monod e Coulanges, chamando-os de positivistas ou de "vencidos de 1870" (cf. REIS, 2000). Como ignorar o ataque de Carlo Ginzburg à Foucault (e aos foucaultianos), quando afirma que a obra do francês bem poderia ser vista como uma nota de rodapé ao pensamento de Nietzsche (cf. GINZBURG, 2008). O anedotário é vasto, mas aqui serve apenas de abertura bem-humorada. 
Pude desde o começo de minha trajetória acadêmica acompanhar algumas polêmicas acaloradas, como a de historiadores marxistas insurgindo-se contra os adeptos da história das mentalidades no início dos anos 1990, destes mesmos marxistas mais afinados com a nova esquerda inglesa contra marxistas simpáticos à obra de Louis Althusser (cf. THOMPSON, 1985), por exemplo. E hoje percebo que enquanto alunos perdiam seu tempo espalhando boatos e mal-entendidos ou realizando leituras enviesadas de correntes historiográficas, ampliava-se sua incompreensão sobre o próprio significado da teoria da história. Acompanhar a censura de Vidal-Naquet aos historiadores alemães em seu revisionismo sobre o holocausto (1995), ou os imperativos éticos levantados por Hayden White em sua justificativa sobre a narrativa e os compromissos do historiador são sintomas evidentes do quanto a escrita da história está marcada por relações de força que merecem reflexão (cf. WHITE, 2006). As disputas da historiografia carioca e paulista em torno do sentido da colonização, colocando em xeque a interpretação de Caio Prado Júnior e, de chofra, a obra de Fernando Novais (cf. FRAGOSO, 1997), ou as críticas que invariavelmente são feitas em relação à História do Tempo Presente revelam que os historiadores não estão imunes a disputas e a partidarismos. Não é, contudo, neste sentido que tomo o conceito de máquina de guerra. Falarei aqui de máquinas de guerra mobilizadas nos territórios da História em escala mundial como a emergência de novas formas de pensamento em reação a formas e práticas tradicionais bem como sobre um dispositivo bastante específico usado nestas disputas, que se apresenta como uma de suas estratégias fundamentais para romperem paradigmas: as revistas de história. Assim, as escolas históricas serão pensadas como máquinas de pensamento, linhas de fuga existentes ou produzidas nas margens dos saberes que emergem ora como resistência, ora como desvio, ora como criação. E as revistas como uma arma pontual de disputa entre determinadas correntes historiográficas.

Uma primeira máquina de guerra do campo surgiu durante a luta para a criação da história científica na Alemanha do século XIX que fundou a ciência histórica, mobilizando filólogos, filósofos, estudiosos da literatura, formando os primeiros historiadores profissionais germânicos que resultou em uma escola histórica seminal, que constituía a História como um saber autônomo, acadêmico, definindo seu estatuto epistemológico e seu método (BENTIVOGLIO, 2011) desvinculando-o dos estudos filosóficos e literários. A outra máquina de guerra é representada pelos combates dos primeiros Annales contra os metódicos franceses, ou mais especificamente de Lucien 
Febvre contra Gabriel Monod e seu grupo junto à Sorbonne. Devo dizer que na França e nos Estados Unidos é mais comum encontrar livros tratando destas polêmicas. François Dosse com seu História em migalhas (2003) é de longe o trabalho mais conhecido a este respeito na França. Entre os norte-americanos um dos polemistas mais recentes é Keith Jenkins, sobretudo em seu On what is history? (2001) ou o também já traduzido no Brasil Repensando a história (1995).

Como se dá a gênese de uma escola histórica? As experiências vividas pela historiografia têm demonstrando que não somente por meio da adesão, mas, sobretudo, pela disputa e pela deflagração da crítica a determinados modelos vigentes. Ou seja, através da mobilização de máquinas de guerra, que são máquinas de pensamento, devires que escapam ou que procuram fugir do establishment e que instauram novos significados ou alargam horizontes dos existentes, abrindo novas searas no pensamento. E elas se organizam em torno de agenciamentos existentes, sobretudo centros de ensino, universidades, departamentos, institutos, associações científicas e grupos de trabalho, brotando quase sempre nas margens para depois se assenhorar dos grandes centros. E necessitam de uma arma pontual na disputa do campo historiográfico: as revistas. Trataremos aqui apenas dos periódicos, mas existem outros dispositivos fundamentais como os livros, as coletâneas, a publicação de séries ou coleções, ou ainda o acesso privilegiado a editoras-chave do mercado livreiro. Isso porque um periódico é uma arma que demarca territórios historiográficos, fundando diretrizes de pesquisa, temas prediletos além de instaurar interditos a vozes dissonantes. Nas palavras de Deleuze e Guattari,

Definimos a "máquina de guerra" como um agenciamento linear construído sobre linhas de fuga. Nesse sentido, a máquina de guerra não tem, de forma alguma, a guerra como objeto; tem como objeto um espaço muito espacial, um espaço liso, que ela compõe, ocupa e propaga. O nomadismo é precisamente essa combinação máquina de guerra - espaço liso (DELEUZE \& GUATTARI, 2006, p.50)

Espalhando-se de forma rizomática, as maquinas de guerra constituem agrupamentos de resistência e desafio, elas não constroem, contudo, hierarquias ou redes de privilégio, mas linhas de fuga, sendo difícil localizar seu começo, apenas seus meios, ou, nas palavras de Foucault, suas genealogias (DELEUZE,2006a, p.352). Tal é o caso de filólogos e filósofos interessados pelo estudo do passado que estavam dispersos em solo germânico mas lentamente conduziram ao nascimento da história científica alemã. Humboldt, 
Ranke, Gervinus ou Droysen, a princípio trabalharam de forma isolada e periférica na gestação desse novo saber.

As escolas costumam surgir quando as carências de sentido apontam os limites e a suficiência das correntes e abordagens históricas existentes ou quando a disputa dos sentidos existentes localiza agenciamentos concorrentes. Isso geralmente ocorre quando uma terceira geração de historiadores herdeiros de uma dada tradição é contestada ou sua posição é reivindicada por uma nova geração. Esse foi o caso, sobretudo de Marc Bloch e Lucien Febvre em relação à geração dos metódicos. Ou da terceira geração de annalistes face aos dois fundadores. Isso muitas vezes revela um certo prazo de validade, um certo esgotamento do potencial explicativo e sedutor de velhos modelos face à emergência de novas possibilidades de pesquisa e análise, algo já elucidado por Jörn Rüsen em seu Razão histórica. O que dá, em média, o que confere perto de um século de evidência para uma determinada escola e sua revista. Elas surgem, adquirem notoriedade, tornam-se referências e em seguida são eclipsadas por outras. Embora as revistas muitas vezes sobrevivam aos seus fundadores e expoentes, o brilho de seus próceres e herdeiros costuma ser ofuscado por novos agenciamentos históricos, por outros centros, periódicos e lugares. Em muitos casos, as revistas, embora tradicionais, precisam incorporar ou acabam sendo incorporadas por novas gerações acomodando novas inquietações e interesses. É o caso da revista dos Annales que se reinventou a partir de 1992 a fim de manter sua posição de prestígio na historiografia contemporânea, ou ainda de outras revistas tradicionais como a American Historical Review. Vale lembrar que as tensões gerações na Revista dos Annales aparecem de maneira inequívoca na própria alteração do nome da revista e na mudança de seus editores ao longo dos anos.

Outro aspecto peculiar que muitas vezes ocorre na formação das escolas históricas é o fato de surgirem nas margens ou periferias e em seguida a partir de disputas ou de alianças lentamente se deslocarem para os grandes centros, incorporando adeptos e expandindo seu alcance, mediante relações de força. Ainda que exista a guerra de posições, ela se dissemina de maneira nômade, em meio a adeptos e simpatizantes distribuídos irregularmente, não só num mesmo país como em países distantes. E também entre leitores e interlocutores. É importante ressaltar que essas máquinas de guerra estão em toda parte, servindo-se das cartografias de poder existentes e que é difícil - no início - percebê-las, elas são o avesso ou a negação sutil dos cânones historiográficos consagrados. Assim, as linhas ou abordagens que usualmente conhecemos, as correntes que seguimos, não configuram mais máquinas de guerra, devem ser entendidas como discursos reconhecidos e autorizados 
na vasta cartografia histórica a exercer relações de poder. Seus fundadores e precursores saíram das margens e tomaram os grandes centros, sem terem, às vezes, alianças prévias. Estas são amarradas depois, com o grupo no poder. Foi assim com Bloch, Febvre e Braudel; com Sybel, Duncker e Droysen; com Thompson, Hill e Anderson na Nova Esquerda Inglesa.

No sentido deleuziano, a máquina de guerra é um devir, um saber que não se submete, em permanente constituição ${ }^{1}$. Centro móvel e nômade, pensamento de recusa. É possível ainda pensar que dentro dos Annales e do marxismo existam estes elementos de transformação, olhares nômades, que dificilmente são acolhidos ou se acomodam na tradição. Foi assim com Veyne e Dosse, ou com Lukács e Benjamin. Ou seja, perspectivas que defendem a liberdade para o pensamento, sua natureza selvagem e a possibilidade de criação constante. O devir é o outsider, é a margem. Mas, enquanto Deleuze não queria discípulos, portanto não existem deleuzianos, no campo da História o esforço é inverso, busca-se identificar, classificar, precisar; assim, espera-se que os pesquisadores se tornem thompsonianos, benjaminianos, foucaultianos, koselleckianos, micro-historiadores, etc.

Deleuze serve-se do mito do guerreiro indiano Indra, que se opõe aos deuses Varuna e Mitra, para ilustrar seu conceito de máquina de guerra. Com ele expressa o vivo movimento de reação às divindades de soberania. Assim,

Máquina é uma "construção", marcada por conexões, fluxos de interesses, de desejos e de necessidades, por agenciamentos que levam a uma espécie de organização, uma composição de linhas de vários tipos: as linhas duras, que amarram e levam a segmentações - das instituições e dos territórios, e as linhas que não se deixam aprisionar - das desterritorializações, que eles chamam de linhas de fuga. São estas últimas, com sua multiplicidade e seus devires, com suas linhas-entre, que fazem a máquina de guerra. (MARQUES, 2009, p. 25).

N'O vocabulário de Gilles Deleuze (2004), François Zourabichvili, sublinha a complexidade daquele conceito, tendo em vista que a máquina de guerra é uma construção que expressa fenômenos de desterritorialização e de descentramento caros às superfícies lisas compostas por variadas linhas de fuga. (ZoURABiCHViLi, 2004, p.33). Deleuze e Guattari, de fato, definem a máquina de guerra relacionando-a ao quanta de desterritorialização, à existência de fluxos nômades, a formas de pensamento que não se deixam aprisionar, que não permanecem extáticas ou herméticas. (DELEUZE \& GUATTARI, 2004, p.112). Tal é o caso, por excelência do pensamento histórico. 
Desenvolvendo um pouco mais o significado e as práticas em torno do conceito, pode-se perceber que o conceito de máquina de guerra possui um aspecto espacial e uma motivação derivada de valores racionais e afetivos. Em relação ao primeiro aspecto, a formação, reprodução e construção do pensamento se reproduz, segundo uma leitura deleuziana, através de superfícies lisas, de maneira nômade, movendo-se pelo espaço não somente ligando um ponto a outro, de maneira linear, mas tal como o impacto de diversas gotas ou jatos de água na água. Seu movimento e permanência são determinados por velocidades, intensidades e devires que se expandem como ondulações irregulares. Nesse tipo de espaço não existem muros ou barreiras, tudo se interpenetra e se hibridiza. A título de contraponto, poder-se-ia dizer que Foucault recorre a metáforas de ordem física - tal como um cartógrafo que explora curvas no relevo acidentado, erosões e falésias -, enquanto Deleuze opera com metáforas líquidas. No tocante aos valores e às ideias, elas são acionadas e urdidas tanto por motivações de caráter racional e epistemológico, quanto por questões de ordem afetiva, o que nos remete, por exemplo, a importância dos ressentimentos ou dos traumas engendrando regras e interditos. As máquinas de guerra são alimentadas por ambos, ou seja, por elementos racionais e afetivos. Estes constituem, em última instância sua força e potência. São estes aspectos que, articulando adequadamente os dispositivos, produziram efeitos de duração e intensidade.

Procurando enquadrar o real no pensamento, buscando paradigmas fixos e estáveis, é comum a crença de que a teoria informa diretamente a prática. Mas as teorias têm sua plasticidade; interpretações e aplicações são feitas de maneira dinâmica em relação aos lugares e aos objetos investigados. E as práticas são dinâmicas, levando à modificação da própria teoria. Jörn Rüsen apresenta uma das melhores soluções para esta aporia: a história preenche, constantemente, carências de sentido em nossa experiência histórica (cf. RÜSEN, 2002). Que todos os saberes são historicamente construídos, já sublinharam Marx, Herder ou Foucault, dentre outros, mas Rüsen tem a propriedade de conseguir demonstrar que o mundo da ciência e da vida prática está em constante relação e mudança. Reportando-se ao problema da consciência histórica, ele revela que tradição, experiência e expectativas são inerentes à vida social e à teoria, em um universo no qual a história é uma disciplina-mãe. Para Rüsen, a teoria da história e a historiografia representam uma tentativa de dotar de sentido carências colocadas pelo presente, demandas mal assistidas, incompreensões. Ele revela que a história tem uma finalidade compreensiva de promover o encontro entre tradições historiográficas, cujo diálogo permite novos olhares sobre o passado, sobre 
o conhecimento histórico, sobre o presente e sobre a tarefa do historiador. Insisto, contudo, que ele confere pouca atenção aos sentidos em disputa ou à saturação dos significados já existentes como fatores de produção e coexistência de práticas disciplinares. De qualquer modo, sua análise reconhece as diferenças de olhares e das posições colocadas. Rüsen não absolutiza a teoria, nem a torna algo extático, imutável. E indica que múltiplas teorias podem e devem coexistir, disputando os indivíduos. E ao disputar os indivíduos, ocupam espaços nos discursos, nos livros e nas instituições. É neste universo que surgem as máquinas de guerra. Nessa linha de raciocínio,

A ciência regida pelos valores morais e valores de verdade são o que Deleuze chama de ciência régia, a qual ele opõe a ciência nômade. A ciência régia tem como ideais a reprodução, a dedução e a indução, e sua lógica é a da reprodução. Reproduzir implica a permanência de um ponto de vista fixo, "ver fluir, estando à margem", já seguir é outra coisa, diz Deleuze (CAMPOS, 2008, p.4).

$\mathrm{Na}$ articulação dos saberes com a sociedade onde são produzidos, a reflexão histórica coloca os homens em contato com sua própria humanidade, com sua própria condição. Como resultado, não apenas produz a necessária digressão sobre as contribuições realizadas, mas, sobretudo, permite o reconhecimento da consciência histórica do historiador e sua autocompreensão conferindo sentido à seu trabalho, revestindo-o de valor social e crítico (cf. GADAMER, 2003). E, do mesmo modo que existem linhas de fuga nos extratos sociais, em sua ação e pensamento, também existem no campo dos saberes. Penso que é irresistível postular, como fez Droysen, que História e ética são uma mesma coisa (DROYSEN, 2009). A história poderia mesmo ser entendida como uma atividade ética que reconhece e imprime à ação dos homens valores e vontades, constituindo comunidades éticas e relações de força. A existência humana para encontrar seu destino e seu sentido exige o conhecimento do passado, a compreensão no presente e o engajamento nos projetos para o futuro. No passado, faraós, reis e imperadores serviam-se da História para firmar seu prestígio, deixando para a sociedade um único relato como garantidor das tradições e dos costumes. No presente, quando a experiência temporal é marcada pelo desejo excessivo de futuro, em um cotidiano frenético marcado pela volatilidade, pela mudança e aceleração, muitas máquinas de guerra são erguidas, o que se reflete na profusão das revistas históricas criadas, todas elas disputando um lugar no interior da história e da historiografia. 
Como se depreende, algumas referências fundamentais informam a análise até aqui desenhada: Michel De Certeau quando este trata da operação historiográfica, Jörn Rüsen e seu entendimento sobre a constituição das matrizes disciplinares, Gilles Deleuze do qual tomo o conceito de máquina de guerra usando-o com uma certa liberdade e, como telos, o pensamento de Michel Foucault, sobretudo em $A$ arqueologia do saber. Certeau, em seminal texto de 1973, no qual discutia a escrita da história, revelou que ela era ao mesmo tempo um lugar, uma prática e uma escrita (CERTEAU, 1997). Um campo de disputas onde conhecimentos, técnicas e abordagens interagem em uma dinâmica de forças. Com Deleuze pode-se pensar a organização espacial dos historiadores ao redor do mundo como rizomática, em uma cartografia complexa na qual diferentes grupos e instituições concentram-se e exercem sua força perante aos fluxos de pesquisa e de conhecimento existentes (DELEUZE, 2000). E nesse conjunto existem aqueles que se aparelham como Estado, apropriando-se das expressões locais e regionais, construindo um discurso uniforme. Essa foi a atuação dos Annales tal como deslindada por François Dosse, a meu ver a maior máquina das máquinas de guerra. Mas, ergueram-se outras máquinas de guerra irredutíveis a esta, exteriores a sua soberania e anteriores a seu direito. Ou seja, os domínios da História, enquanto conjunto de saberes, objetos e abordagens, é muito maior do que qualquer corrente historiográfica. A História, sob este ângulo, poderia ser vista como uma ciência excêntrica. Deleuze e Guattari, ao tratarem da ciência excêntrica dizem que ela se vincula às máquinas de guerra e que se expande "por turbulência num espaço liso, em produzir um movimento que tome o espaço e afete simultaneamente a todos os seus pontos, ao invés de ser tomado por ele como no movimento local, que vai de tal ponto a tal outro". Assim, ela tem um caráter desterritorializado, apatriado. $\mathrm{O}$ pensamento nômade não opera segundo as categorias universais do pensamento clássico, o todo e o sujeito. É um devir, um pensamento não-globalizante. A historiografia, com suas diferentes correntes e postulados teórico-metodológicos abrigou várias máquinas de guerra, cujas tarefas maiores foram a de resistir e a de criar. Uma ciência ligada à máquina de guerra não está destinada a tomar um poder e nem sequer a ter um desenvolvimento autônomo, ela reconhece seus limites, interdependências e sua duração. Em alguns momentos, as máquinas de guerras podem ser de destruição e de morte, como quando são apropriadas pelo aparelho de Estado com o objetivo de exercer a guerra e eliminar as rivais. ${ }^{2}$

Como afirmam Deleuze e Guattari, 
Não é em termos de independência, mas de coexistência e de concorrência, num campo perpétuo de interação, que é preciso pensar a exterioridade e a interioridade, as máquinas de guerra de metamorfose e os aparelhos identitários de Estado, os bandos e os reinos, as megamáquinas e os impérios. Um mesmo campo circunscreve sua interioridade em Estados, mas descreve sua exterioridade naquilo que escapa aos Estados ou se erige contra os Estados (DELEUZE \& GUATTARI, 2006, p.24).

Tomo a liberdade de inserir nesse quadro a História. Examinemos a primeira máquina de guerra. Ela foi responsável pela constituição da ciência histórica na Alemanha ainda na primeira metade do século XIX. Conhecida como Escola Histórica Alemã ela reuniu um conjunto heterogêneo de historiadores, capitaneados, inicialmente por Wilhelm von Humboldt, Leopold von Ranke e Barthold Niebuhr e, posteriormente, foi ampliada por seus discípulos e herdeiros. Todos eles foram responsáveis pela constituição da autonomia epistemológica da História, tornando-a um conhecimento específico, apartado da filosofia e da literatura, em cuja tensão a própria História foi erigida como uma máquina de guerra. Dentre os historiadores herdeiros desta tradição encontramos: Jonhann Gustav Droysen (1808-1886), Heinrich von Sybel (1817-1895), Heinrich von Treitschke (1834-1896), Max Duncker (1811-1886), Rudolf Hayn (18211901), Theodor Mommsen (1817-1903), Lüdwig Häusser (1818-1867) e Georg Gottfried Gervinus (1805-1871). Depois de consagrarem a história como um campo científico autônomo, uma nova geração, composta, dentre outros, por Max Weber (1868-1922) e Wilhelm Dilthey (1833-1911) em particular, foi responsável pela criação de novas máquinas de guerra, desta vez deslocando e alargando o campo histórico para os territórios da sociologia. Como estratégia dos fundadores alemães, havia a adesão ao historicismo, a simpatia pelas idéias liberais, a defesa do constitucionalismo, de maneira que não separavam a produção de conhecimento da atuação política; a fundação de uma revista a Historische Zeitschrift de 1859, veículo divulgador daquela escrita da história, criada e editada por Heinrich von Sybel, e tendo como colaboradores Mommsen, Treitschke, Droysen, Gervinus, Haym e Duncker, dentre outros (SOUTHARD, 1995), sedimentou a expressão e a influência daquele grupo. Ela foi uma das primeiras revistas de História do mundo. Quase todos aqueles historiadores escreveram, em algum momento, textos sobre a história germânica e sobre sua política contemporânea. Como método adotaram a hermenêutica e a 
crítica histórica ou crítica documental, tal como proposta por Niebuhr e depois por Ranke. Defenderam a existência autônoma da História, como um conhecimento científico, a teoria da história como campo privilegiado de reflexão sobre o método e a historiografia e a filosofia da história como objetos específicos no interior do próprio saber histórico. Criaram cadeiras de história em várias universidades alemãs. Um curso específico passou a funcionar na Universidade de Berlim. O poder alcançado pelos escritos do grupo cruzou fronteiras, não só na Europa, mas chegou até a América e o Oriente. Traduções de seus livros podem ser encontradas no final do século XIX feitas tanto nos Estados Unidos como no Japão. A base do grupo, que desde o início esteve difusa entre Iena, Bonn, Heidelberg, Göttingen e Leipzig, vai lentamente se deslocando para Berlim. O pensamento historiográfico que produziram dialogava criticamente com o iluminismo, o romantismo ${ }^{3}$, com a filosofia de Kant, o hegelianismo ${ }^{4}$ e o historicismo (cf. MEINECKE, 1994). E tinha um forte teor nacionalista, talvez, o principal ingrediente a ser incorporado pela escola metódica francesa, nitidamente inspirada nesta tradição historiográfica germânica. A crítica do diletantismo na pesquisa histórica, a criação da carreira acadêmica, a constituição de um corpo teórico-metodológico, a reflexão sobre a escrita da história, todas essas foram conquistas feitas e praticadas por esta primeira e seminal máquina de guerra da História, responsável pela gênese deste saber no século XIX. Compostos na confluência de inúmeras linhas de fuga constituíram um modelo vigoroso de história propagado pela Historische Zeitschrift que se passa a ser visto de maneira homogênea, em outras palavras, como uma escola histórica. E entendida como um grupo coeso, embora se dividisse em inúmeras subcorrentes e apresentasse historiadores bastante heterogêneos (BENTIVOGLIO, 2011), exerceram poderosa influência na historiografia ocidental. E como essa corrente era vista pelos historiadores contemporâneos? Para os metódicos franceses eram apenas pedantes e germanófilos, para os Annales eram obscuros e positivistas e, para os marxistas historiadores ultra-conservadores e reacionários.

A outra máquina de guerra ergueu-se na França, mas longe de Paris, por meio de Marc Bloch e Lucien Febvre que a partir de Estrasburgo combateram a fortaleza metódica encastelada na Sorbonne e na República Francesa ${ }^{5}$. Embora incorporassem pressupostos desenvolvidos na Alemanha, revestiram seus postulados com o espírito francês, avesso à erudição e à especulação filosófica. Os Annales assumiram melhor o contato com o pensamento germânico, ao contrário dos metódicos que tentavam o obliterar sem sucesso. Máquina das máquinas de guerra, os annalistes 
também constituem uma revista, a revistados Annales em 1929, cujas alterações em seu nome, ao longo de décadas, revela a heterogeneidade, bem como as disputas no interior do próprio paradigma. Por que Bloch e Febvre criaram uma nova revista se havia a Revue de Synthese de Henri Beer onde já publicavam? Porque este não quis fundar uma escola, não queria arrebatar seguidores, dirá Dosse (DOSSE, 2003, p.45). De certo modo, aponta Nilo Odália no prefácio de A Escola dos Annales que o surgimento do grupo pode ser encontrado no descontentamento de um jovem grupo de historiadores com a história política e a história acontecimento de seu tempo. Eu acrescentaria ainda que, como outsiders, o grupo de Estrasburgo lançava protestos contra a hegemonia de Paris, nas universidades, nas publicações, repartições públicas e nos livros didáticos. Foi Koselleck quem disse que os melhores historiadores são sempre exilados (2002, p.42). Lembro ainda que Estrasburgo era uma universidade germânica entre 1871 e 1918 e que a presença de Bloch e Febvre por lá se deu em um momento fecundo de renovação, de reconstrução.

De maneira engenhosa, os Annales fizeram alianças com as ciências sociais e procederam a uma verdadeira revolução na historiografia, eclipsando a importância de paradigmas rivais, sobretudo o marxismo, do qual incorporou adeptos e ex-adeptos, bem como alguns pressupostos analíticos. Após uma década de combates, Bloch e Febvre sucedem os historiadores metódicos no controle da Universidade de Paris, disputando com eles o cenário historiográfico até a chegada da Segunda Guerra Mundial, quando então seus discípulos e herdeiros se tornariam incontestes, pelo menos até meados dos anos 1980. De início restrita a trabalhos publicados por historiadores franceses e referentes à França, paulatinamente sua revista se internacionaliza, abriga colaboradores estrangeiros, impõe uma maciça produção bibliográfica que é traduzida e conhecida no mundo inteiro. Facilitam o acesso a seus centros de pesquisa e a seus programas de pós-graduação a pesquisadores de todo o mundo. Talvez maior do que o conjunto de todos aqueles que foram para outros países e centros. Entre seus expoentes, Georges Duby presidiu o canal 7 francês, Pierre Nora foi editor na Gallimard. Embora Febvre tenha sido mais aguerrido nos combates pela história, Marc Bloch, em seu Apologia da história, revela: "a história serve à ação". Ou seja, a atuação do grupo não deixa dúvidas quanto a suas estratégias de alcançar o centro do poder, conforme aponta François Dosse. A ênfase foi a crítica sobre o domínio da história política tradicional, que passa a ser bastante contestada já no final do século XIX, inicialmente pelos historiadores econômicos, como Schmoller em Estrasburgo ou por 
Max Weber. Durkheim, Simiand e Comte fizeram as mais duras críticas a esta história de superfície e de genealogias reais. Na Alemanha coube a Karl Lamprecht este papel. Mas os ataques de Simiand aos ídolos da tribo dos historiadores (político, individual e cronológico) foram demolidores e auspiciosos. Ali era denunciado um dos expoentes dessa história condenável: Charles-Victor Seignobos, discípulo de Lavisse, amigo de Monod e professor na Sorbonne. Talvez por isso ele tenha se tornado o alvo e símbolo de tudo aquilo que a nova geração de historiadores veio a criticar. Nem é preciso dizer o quanto muitas das críticas aos metódicos eram exageradas e ainda equívocas.

Esses dois exemplos abordados rapidamente ilustram a factibilidade e a presença das máquinas de guerra nos domínios da História. No mundo globalizado de hoje, onde são sofisticadas, silenciosas e violentas as relações de poder, o conhecimento histórico não está imune a elas. Também ele vive em meio a ameaças e disputas constantes. De certo modo, vislumbram-se ainda os Estados Unidos, a Alemanha e a França como sendo epicentros de vigorosos fluxos e fomentadores de muitas novas abordagens históricas. Tanto no tocante à gestão e financiamento da pesquisa, como também irradiadores de novas correntes teóricas. Mas é forçoso lembrar, por exemplo a emergência da microhistória italiana como uma nova abordagem que se erigiu às margens destes grandes centros. Desde a Segunda Guerra Mundial é comum a presença de intelectuais, particularmente europeus, em universidades americanas. E desde então, é cada vez mais freqüente o acesso de novas teorias no Brasil a partir de leituras americanas. Adorno, Marcuse e Fromm, mas também Foucault, Ginzburg, Lyotard, Barthes, Derrida e hoje Rüsen e Gumbrecht, dentre vários outros fizeram sua peregrinação à América. Foi via lingüistic turn que ecoou junto aos historiadores brasileiros o problema da narrativa histórica, que se colocou o debate sobre o pós-modernismo ou do pós-estruturalismo - os americanos adoram este prefixo, como se modernismo e estruturalismo tivessem esgotado suas forças. Da França, continuam surgindo expressões vigorosas para a História, em que Foucault ou Deleuze, por exemplo, são nomes significativos. Da Alemanha a produção de autores como Rüsen, Koselleck e Gumbrecht atestam formas diferenciadas e influentes para a pesquisa histórica contemporânea. Tais fluxos que atualmente impactam a historiografia recente impondo-se como novas reflexões que se colocam para a produção do conhecimento histórico tratam de aspectos relevantes referentes ao relativismo, ao redimensionamento da aliança com as ciências sociais, à problematização da narrativa histórica, à necessidade 
de se realizar novas sínteses, à discussão sobre o estatuto do real dentre outros, que sublinham o quanto as críticas e os desafios colocados aos historiadores alimentam a formulação de novas abordagens e ferramentas metodológicas. E também contribuem para se forjar novos instrumentos de reflexão e análise. Tudo isso expressa a efervescência que alimenta a formação de novas máquinas de guerra. Paralelamente a isso, na condição de ciência excêntrica, a história também vive o retorno a Dilthey ou ao historicismo alemão, por exemplo, que não se faz por acaso (cf REIS 1988, 2000). Assim como Bloch e Febvre em sua crítica aos metódicos releram Voltaire e Michelet, os historiadores do presente estão redescobrindo os românticos e o historicismo e voltam a pensar nas singularidades como antítodo à massificação e às sínteses, recorrendo ainda às sensibilidades para combater os excessos da racionalidade, além de insistirem nas especificidades da ciência histórica face às demais ciências humanas. Vislumbra-se, igualmente um abandono paulatino da experiência coletiva (erfharung) em algumas expressões historiográficas e um retorno das vivências individuais (erlebnis). Igualmente temos a manutenção do apreço aos Annales ou ao marxismo em diversos historiadores contemporâneos. Da era das explicações, passando pela das interpretações, volta-se a defender a compreensão como cerne da operação historiográfica, embora Gumbrecht denuncie uma certa saturação da hermenêutica. Redobram-se as preocupações sobre a escrita e o estilo na História (cf. WHITE, 2002 e GAY 1990). Ao pretendido mal-estar da história vive-se, ao contrário, um estado vigoroso e fecundo no qual os historiadores não abdicam de seu compromisso permanente de erigir novas máquinas de guerra.

HISTORIOGRAPHY AND WAR MACHINS: THE HISTORY OF HISTORY AS A CAMP OF forces STUdy With brief NOTES ON THE German Historical School and ANNALES SCHOOL

Aвstract: This paper aim to analyse the German Historical School and the School of Annales taking the concept of war machines - perspective opened by Deleuze - and the reflections of the Michel de Certeau's historiographical operation. It shows how the power relations within the historiography and the creation of specific devices, the historical reviews, mark the advancement of this knowledge, the History, which is constituted as an excentric field whose effects are irregular in the time and in the space, since it is both a place, a discipline and a writing, that emerges in tension whit other knowledges and in the disputes between differents historiographical trends.

KEYwORDs: Theory of history, historiography, war machines. 


\section{NOTAS}

1 A discussão está em DELEUZE e GUATTARI, F. Mil Platôs: capitalismo e esquizofrenia. Tratado de nomadologia. São Paulo: Ed.34, v.5, 1997.

2 Cf. Marcelo FRANCO. Ciência e Filosofia: o niilismo em Nietzche. Informática na educação, n.7, março/2000, disponível em http://www.ccuec.unicamp.br/revista/infotec/educacao/educacao7-1. html. Acesso em 20 de outubro de 2008.

3 Em sua vertente nacionalista que buscava as raízes da língua e da nação alemã.

4 Droysen foi aluno de Hegel.

5 Ver dentre outros BURKE (1996) e DOSSE (2003).

\section{REFERÊNCIAS}

Bentivoglio, Julio. A Historische Zeitschrift e a historiografia alemã no século XIX. História da Historiografia, n.6, p.81-101, 2011.

Burke, Peter. A escola dos Annales. São Paulo: Ed. Unesp, 1996.

CAmpos, Luana B. O cinema nas potências do falso. Travessias, n.2, 2008.

Certeau, M. A operação historiográfica. In: A escrita da história. Rio de Janeiro: Forense Universitária, 1997.

Deleuze, Gilles e Guattari, Felix. Mil Platôs: capitalismo e esquizofrenia. Tratado de nomadologia. São Paulo: Ed.34, v.5, 1997.

Deleuze, Gilles. Conversações. São Paulo: Ed.34, 2000.

Deleuze, Gilles. Cinco proposições sobre a psicanálise. A ilha deserta e outros textos. São Paulo: Iluminuras, 2006a.

Deleuze, Gilles. Diferença e repetição. Rio de Janeiro: Graal, 2006 b.

Dosse, F. História em migalhas. Bauru: Edusc, 2003.

Droysen, J. G. Manual de teoria da história. Petrópolis: Vozes, 2009.

Febvre, L. Combates pela história. Lisboa: Presença, 1989.

Fragoso, J. L. Homens de grossa aventura. Rio de Janeiro: Civilização Brasileira, 1997.

Franco, Marcelo. Ciência e Filosofia: o niilismo em Nietzche. Informática na educação, n.7, março/2000, disponível em: <http://www.ccuec.unicamp.br/revista/ infotec/educacao/educacao7-1.html>. Acesso em 20 out. 2008.

GAdAmer, H-G. O problema da consciência histórica. Rio de Janeiro: FGV, 2003.

GAy, Peter. O estilo na História. São Paulo: Companhia das Letras, 1990.

Ginzburg, C. Entrevista a Maria Lúcia P. Burke. Disponível em: < http://teoriahistoria.blogspot.com/2008/09/entrevista-com-carlo-ginzburg_852.html>. Acesso 2 set. 2011. 
JENKIns, K. On what is history? Londres: Routledge, 1995.

Jenkins, K. Repensando a história. São Paulo: Contexto, 2001

Koselleck, R. Estratos del tiempo. Barcelona: Paidós, 2002.

MARques, Davina. Literatura como máquina de guerra. Letras, v.19, n.1, 2009.

Meinecke, F. El historicismo y su genesis. México: Fondo de Cultura Econômica, 1987.

REIs, José Carlos. História e teoria. Rio de Janeiro: FGV, 2000 ou A história entre a filosofia e a ciência. São Paulo: Ática, 1988.

Reis, José Carlos. Os combates de Febvre. In: __. Escola dos Annales: a inovação em história.

São Paulo: Paz e Terra, 2000.

RüsEn, J. A razão histórica. Brasília: Ed.Unb, 2002.

Southardt, Robert. Droysen and the Formation of the Prussian School. Lexington: University Press of Kentucky, 1995.

Thompson, E. P. A miséria da teoria. Rio de Janeiro: Zahar, 1985.

VIDAL-NAQuet, P. Les assassins de la mémoire. Paris: Seuil, 1995.

White, H. Metahistoria. São Paulo: Edusp, 1998.

White, H. Enredo e verdade na escrita da história. In: MALERBA, Jurandir (org.) A história escrita: teoria e história da historiografia. São Paulo: Contexto, 2006.

Zourabichvili, François. O vocabulário de Deleuze. Rio de Janeiro: Relume Dumará, 2004. 